\title{
Systemic Approach to Failure Analysis: A Study of Sociotechnical Organization
}

\author{
Nasir Afghan ${ }^{1}$
}

\begin{abstract}
The paper is an attempt to explore the systemic approach to accidents analysis within socio-technical organizations. Unsafe behaviors can result in systemic failures and accidents. The research data came from within an industrial radiography organization where a radiation source is used to detect cracks or hidden flaws within machinery and welding joints. The radioactive source can cause severe detrimental effects, even death, if not used safely. This paper is on two isolated events that happen in the same company, Industrial Services Private Limited (not real name). The company's top management was dealing with the financial crisis and to maintain the quality of its services and the safety of staff. The leadership of the company made several business and operational decisions to manage the financial crisis. During that time, several near-miss incidents took place, but the first major incident took place when the radiography gamma projector, along with the radioactive source, fell out of the vehicle because of improper back door closure of the vehicle. In the second incident, the radioactive source remained unshielded after a radiography job, this caused overexposure to radiography workers. The paper provides an opportunity to understand how an organization's leadership can create conditions for errors and mistakes that result in poor safety culture and ultimately the accident which resulted in the system failure and operation shutdown. The paper also tries to propose a conceptual framework to improve the safety culture within the sociotechnical systems for the future research in this area
\end{abstract}

Keywords: Crisis management; leadership; systemic failure analysis

\section{JEL Code:}

\section{Introduction and Background of the Paper}

The objective of this paper is to understand the systemic failure and accident within the sociotechnical (technology-focused) business organization. Case studies on systemic failures are essential to have a deeper and better understanding of the safety culture as a systemic concept (Dekker, 2011). Work culture is an emerging and dynamic concept (Reiman, 2014) which evolves from the interaction of people in working groups, within socio-technical organizations. (Vaughan, 1996) Explained this process as the production of culture. Workgroup culture and tasks related behaviors are the result of the interaction between people within the workgroups to perform technical tasks. Culture is people's way of doing things while dealing with technology and

${ }^{1}$ Department of Business Administration, University of the Punjab, Gujranwala Campus.

Corresponding Author: 
organizational systems (Reiman, 2014). Organizational culture belongs to the group of people working together (Schein, 1985, 2004, 2013a), "the way we do safety around here" (IAEA, 2016a). Workgroups share this common working knowledge, assumptions, norms, beliefs, and behaviors with the new workers joining the workgroup due to its practical usefulness and its effectiveness as a glue for the workgroup performance. Safety culture is well defined as a normative concept as mentioned by (Reiman, 2014). Desired safety-related behaviours, safety rules and regulations, and safety goals and objectives are normative. The set of safety standards and policies, guidelines, SOPs are defined, set before, as per the complexity of the technology, tasks and organization's objectives and process needs. Therefore, "safety culture" has both normative dimension and emerging (culture) dimensions, which makes this concept more complex and systemic (interconnected and dynamic at system levels). Safety culture is deeply rooted and integrated within the specific sociotechnical system. Every sociotechnical complex system develops its own safety culture understanding, definition, and its useful practical implications, which may or may not have the relevance for other organizations. Also, it is also possible that having the safety culture definition and policy in the documents does not mean that the same safety culture concept is part of workgroup every day doing things and within the overall organizational working process. Hence, there are hundreds of definitions of safety culture because every sociotechnical organization and industry sector defines its own safety culture definition as per their complexities, experiences, needs, and worker knowledge and skills. Due to the systemic nature of the safety culture within the sociotechnical system, one small safety violations or error could lead to a big systemic failure and big accident (Fortune, 1994, 1995). Due to the dynamic interconnections (relationships) between different components, at organization levels and due to humantechnology interfaces.

Therefore, we must understand how organizational-level decisions and actions influence unsafe behaviours and create systemic failures and incidents. It is important to know, how can the small violation of safety culture in an organizational system can creates systemic failure. Rather than saying, the accident is due to the human errors or technical failures we need to understand the systemic nature of safety culture in the organization. Secondly, how to manage such a dynamic and normative concept within the complex socio-technical system? This is what we have tried to understand through this research. Furthermore, there are apparently enough definitions of safety culture, therefore no need to add one more definition. For us, safety culture within the sociotechnical system must have both, desirable safe behaviours and not so desirable safe behaviours and actions, the dos and the don'ts. The logic of having this dual consideration is that work teams must set norms, assumptions, values, and behaviours that will have a positive influence on safety, as well as workgroups must clearly define relevant negative norms, attitudes, faulty assumptions, and unsafe behaviours that will have potentially negative influence over safety outcomes. Most of the time accidents are due to negative safety norms, negative values, wrong assumptions, and unsafe actions. Safety culture in organization must define what is safe and what is not safe 
behaviours for everyone within high risks sociotechnical systems. There is a managerial choice, if a manager's safety culture is understanding and if his or her actions are safety positive within the sociotechnical system, safety will remain positive otherwise negative safety outcomes and accidents will happen in the organization. Work group must also be able to recognize and stop the negative safety culture, unsafe norms, faulty assumptions and poor safety behaviours before the accident.

\section{The Case Study (ISPL)}

After the selection of two events (which happen in the same organization) from IAEA website, the researcher conducted interviews with the radiation protection officer (RPO) within the organization. Also interviews with operational level staff members of the organization and collected details and officials report from other sources regarding those two incidents. According to one employee "there were several other small incidents in the last 15 years in our organization". However, the present paper focus is only on those two reported incidents. First, a detailed case study on the organization was completed, which provided the organizational context and the details on the actual accidents. The case study provides details on the challenges and issues faced by the management and specially the management dilemma of safety culture vs production operation within the organization. The case study development and analysis help us identify the systemic level safety assumptions and actions taken by the top leadership of the organization during the crisis.

\subsection{The Case Study}

Industrial Services Private Limited (ISPL name changed) started its operations in early 2007. It quickly became a renowned company for its services related to industrial radiography (IR), and other non-destructive testing. The company used to provide services not only at plants sites but also on pipelines at remote areas, throughout the country. However, the competition in the radiography services industry started to pick during 2012 and 2014 in the country. The devaluation of local currency in the country in 2015 influenced negatively on ISPL profitability. In 2015, the company was facing multiple challenges to maintaining its quality of services with the existing cost structure. In addition to this, the cost of provisions of services like price of a radioactive source, calibration of equipment, transport and other charges also increased considerably ( $40 \%$ increase in the last one year). Meanwhile in 2016 due to the changes in the regulatory commission national act, the regulatory commission increased the licensing fee significantly (i.e., doubled). National Radiation Protection Commission (NRPC) also implemented new regulatory and safety requirements for licensees. New safety and security requirements were introduced in accordance with IAEA (2011) safety and security standards. According to one employee "Regulator imposed more strictly regulations such as regular staff training, staff requirements in a shift, and the management and leadership for safety procedures and policies, security of the sources". Due to these regulations and external economic factors, the company was facing declining profits starting 2017. Several clients complain to the CEO that their services prices are comparatively on the higher side and if they did not reduce prices, the contract

Sukkur IBA Journal of Management and Business - SIJMB | Vol 8 No. 2 July - December 2021 (C) Sukkur IBA University 
will go to other competitors. Mr. George (CEO) shared these concerns with his top team and radiation protection officer (RPO) during the company annual strategic meeting in March 2018.

In April 2018, to manage the high costs of operations and other tax-related financial implications, the company reduced laid off $20 \%$ of workers and reduced it from total 80 workers to 65 workers. The workers who were released from the company, including the Director (Operations), radiography workers, account and HR related people. The company also adopted a policy to allocate two technical personnel for a radiography source instead of its previous practice of three (technical) persons per radiography source. The policy of three per person in a radiography operation within the industry is a "Good Practice", however, the two-person policy was fulfilling minimally the IAEA recommendations for workforce availability at site radiography activities. According to $\mathrm{RPO}$, the CEO, the director (technical) and director (finance) all felt that, apart from necessary regulatory requirements like detection equipment, personal dosimeters, transport vehicle, health surveillance, etc. many other regulatory requirements were merely a paperwork and did not contribute to improving the safety culture and personnel safety. These additional operating requirements included to have a well-established management system, positive safety culture in the organization, leadership for safety and independent safety assessments in organization etc. In addition, the top management team thought that these extra regulatory requirements were the replica of IAEA standards and were applicable only to the nuclear power industry instead of radioactive sources. The National Radiation Protection Commission (the regulator) inspectors were also softly urging the ISPL senior management, the users of radioactive sources, to apply these requirements in contrast with other strict requirements of radiation safety like equipment, calibration, dosimeter, etc.

Mr. George and his Director (Technical) Mr. Mark believed they should not be subject to these high safety requirements since they never had any accident in the company. According to RPO our CEO said, "We never had safety risks like nuclear power plants, why should we be following those policies and procedures"? The company management was reluctant to follow the recommendations, on safety culture, by the NRPC safety documents. The repair \& maintenance policy was also restricted to the most important items and preventive maintenance activities were postponed reducing the operational cost. The new operational policy was implemented without any incident and employees adjusted to the situation accordingly. However, due to a smaller number of trained technical workers, there was an indication of an increase in personal radiation dose in the first few months but since the personal doses were still below the regulatory limits, the company and the shift supervisors and the senior manager did not give much attention to this issue. The average dose per worker was $8.4 \mathrm{mSv}$ for year 2018 in comparison with $6.7 \mathrm{mSv}$ per year for the past three years. With the same volume of radiation work, which indicated a decline in the occupational radiation safety procedure. However, the RPO was concerned, and he reported this anomaly to Mr. George and the Director (Technical) Mr. Mark regarding the increase in workers doses. Mr. George suggested to RPO to "increase workers incentives" if they work in extra shift to Sukkur IBA Journal of Management and Business - SIJMB | Vol 8 No. 2 July - December 2021 @ Sukkur IBA University 
compensate their extra efforts. On 6th Feb 2019, the RPO informed to the regulator during their inspection to the company office that one radiation worker received $8 \mathrm{mSv}$ in 6 months which was considerably higher than his previous dose record for the same duration. Director (Technical) felt that this dose was still under the regulatory limits and, after some training and mentoring of that specific radiographer, he could still do the job as needed. An inspector of the regulatory body observed the record of the radiation doses during the inspection but noted no violation of regulatory requirements because the dose was still under the limits. However, the inspector indicated during his personal discussions with the RPO and he asked him to report to regulator if any "further increase in the do or any incident to NRPC without any delay" and the RPO promised to comply with the advice of the inspector. The inspector said to Mr. John (RPO) "It seems that your top management does not gives due respect to the regulator they are ignoring safety standards and they have been ignoring our feedback on declining safety again and again".

The first incident, on $22^{\text {nd }} F e b 2019$, the company radiography team was engaged in an operation in a remote area outside the city. The team comprising of two persons, i.e. one radiographer and one Technical Assistant (TA), completed a long day job at the power plant and were returning to another location for further radiography job. The vehicle malfunctioned on the way back to the city in the midnight. One of the team members was driving the vehicle and he knew a little bit how to repair the vehicle engine. He opened the back door of the vehicle, took some necessary equipment from the rear cabin for the maintenance of the vehicle and did the repair job. After maintenance of the vehicle, the journey was a resume. Before reaching the radiography site, the radiographer checked the reading on the radiation survey meter and discovered that the projector (the radioactive source) was not present in the vehicle. He immediately recognized that the projector had fallen from the vehicle because the back door, which was not close fully after the maintenance work. The team started searching for the projector alongside the road. Meanwhile, a shopkeeper contacted the radiographer at his mobile phone and informed that the container was in his custody because his phone number post on the source container box. Consequently, the projector recovered from the shopkeeper.

The team performed a detailed radiation survey and verification of source from its pigtail number. Fortunately, everything was found satisfactory and unharmed and there was no damage found to the physical condition of the source container. In the next morning, the incident was reported to the company's top management and the regional office of the national radiation regulatory commission. The company's management suspended those two workers for two months. The regulatory body conducted a special inspection and instructed the company to improve safety and security standards and SOPs because as per IAEA security standard the ease of handling of these devices and their presence in vehicles outside secured facilities make them attractive for unauthorized removal. However, safe restoration of the source was a matter of relief for all parties. Mr. George and Mr. Mark believed no radiation exposure to public or 
radiation workers, everything was in fine shape at the end and there was no need of any further action. In an internal meeting with the RPO and other technical field staff, the CEO and Director (Technical) decided not to report such small incidents to the NRPC in the future. According to one staff member, Mr. George said in the meeting, "we need to be more careful next time, and we need to keep these small incidents to ourselves and no need to show our weaknesses to others". No one in the meeting, including RPO, objected or shared any disagreements with the CEO comments. They all agreed to be more careful next time and meeting was over after 10 minutes without many discussions. Around mid-May 2019, the company signed a large contract with a pipeline company for performing the industrial radiography in remote areas. The contract was tightly scheduled and complicated because of many activities on different locations in parallel, everyone was happy with this large contract.

The second incident, on November 5th, 2019, two radiography jobs were planned by RPO on the same day at two different locations (A and B) some $100 \mathrm{~km}$ apart from each other. The company decided to use a single team of two persons with a high activity radioactive source to perform both jobs. The RPO was a bit cautious due to high activity and briefed the team accordingly. However, he instructed the team (comprising of Mr. Michael (Radiographer) and Mr. Jack, (TA) to conduct first job early in the morning and second job in the evening on the same day and return to the city office where source storage pit was located. In doing so, the PRO planned to save any rental charges at the site B for overnight stay. RPO further instructed the team to use an old and repaired guide tube and gamma camera projector instead of the new one. The new one he planned to use for another job at a different plant site due to strict quality control measure by the other plant management. The team left the city office, early in the morning on 5 November 2019, for the radiography job at site A. The team decided that one person would do the job so that the other person could take the rest during the long day work. The first job was done in 5 hours as per schedule, the gamma camera and the guide tube did not offer any problem during the job at the site A. During the journey to the site B, they were stuck on the highway in an unusual traffic conjunction. After spending some two hours, the highway police cleared the traffic, and it was a road accident. The journey afterward to site B was also a bit slow, which further delayed their arrival at site B. One team member said to the other "in good days, this second job would have been done by other team or on next day, but prevailing financial crunch have forced us to do both jobs without any rest". They had to perform both radiography jobs on the same day and go back on the same day and report next morning. The team arrived at site B a little late in the evening, had a quick meal, and started their job. They completed their second job before the midnight. Exhausted from the two radiography jobs and the journey, they tried to stay at the site but there were no prior arrangements for their stay and source storage. Furthermore, they tried to call the RPO who did not pick up the call from the team. Disappointed with the situation, the team decided to come back to the office late in night. They quickly assembled their stuff and put it in the vehicle. During the quick actions, they missed performing a final safety survey to ensure that the highly active radioactive source was intact in the shielded gamma projector or not. In fact, the

Sukkur IBA Journal of Management and Business - SIJMB | Vol 8 No. 2 July - December 2021 (C) Sukkur IBA University 
radioactive source was not in the projector (not shielded) and was still in the guide tube in the exposed position. The team placed all stuff inside the vehicle and drove all the way to the city office in a 3.5-hour journey. When the team reached the city office pit around early morning at 6:00 am, when they started to shift the stuff, they realized that the source was not in gamma projector. Mr. Michael, the radiographer turned on the survey meter, which showed a very high radiation reading, indicating that the source was being unshielded. Realizing the seriousness of the situation, they got scared of the high radiation level; they quickly placed all the stuff in the storage room and informed the RPO and the duty guard. The RPO responded to their call and reached the office urgently in next $30 \mathrm{~min}$. The RPO restored the source from the guide tube to the gamma projector. He used only the active dosimeter in order to avoid excessive radiation dose to the passive dosimeters. In the next morning on 6 November 2019, the matter came to the knowledge of Mr. George and Mr. Mark. They decided that, since the source was intact, there was no need to inform the NRPC regarding the incident. Since, the RPO did not use passive dosimeters; there was no chance of any overexposure on his badge. They further decided to pretend that the passive dosimeters of the two working radiographers had been lost during the long journey and their recovery was not possible since they have no idea about the exact location. Mr. George (CEO) and Mr. Mark, Director (Technical) decided to cover up this incident. The two potentially overexposed persons Mr. Michael and Mr. Jack were briefed that the event took place entirely because of their mistake. To avoid further penalty, they got instructions to stay silent. The company gave them a leave until further instructions and paid them some amount for better food and medical treatment, if needed. A short while ago, Mr. Jack, TA started to feel nausea followed by vomiting and headache. Mr. Michael also felt the same condition. Both contacted with the company and the company provided them some help but they wanted better medical treatment facility, which ISPL management declined due to financial reasons.

\section{Discussions}

The organization's misconduct (Vaughan, 1996) starts due to competitive pressures, resource scarcity and peer pressures. These underlying conditions created productionfocused behaviour and safety rules violations. The risky decisions making and accepting the risks and the normalization of deviance starts within the case organization. The organization culture becomes a task and result-oriented and "we must keep these incidents in the organization" was the cultural norms in the organization. However, top management was trying to overcome the challenge to balance the tradeoffs between safety and production. It is apparent that Safety $1^{\text {st }}$ rule and production $2^{\text {nd }}$ in all toplevel decision and middle levels operational decision within this high risks and highreliability organization was difficult to practice. The CEO and the top leadership were more inclined towards achieving production and financial targets. It is important for us to see how the higher leadership's decisions making influences the overall safety culture within the organization and how it influences and endangers human safety and organizational sustainability. It is also critical to understand the field technical staff dilemmas. The field technical staff are from lower hierarchy levels (high school

Sukkur IBA Journal of Management and Business - SIJMB | Vol 8 No. 2 July - December 2021 (C) Sukkur IBA University 
diploma holders) and they felt powerless. They were unable to share freely their concerns and safety issues with the senior managers during the project meetings. The case provides an evidence that lower technical workers in the organization have also no support and encouragement from the director technical and the RPO in the organization to speak out and share their concerns with the CEO and top management. The lowerlevel field technical staff lost interest of following safety behaviours and begin ignoring SOPs during day-to-day activities. On the other hand, during the financial crises and amidst the firing of staff, the lower-level staff members tend to keep quiet. Lower staff were following the orders in the hope of saving their own jobs. They were afraid to speak and share their views on safety-related issues not just to protect their own jobs but show loyalty and commitment to the top leadership decisions and actions.

Organizational misconduct was in full play, starting from top leadership to middle and towards the lower-level managers and staff in the organization. It seems to practicing and follows a safety culture becomes a major challenge, for the top leadership of organizations and for the middle-level managers, when the organization is under financial pressure to cut operational costs while maintaining its profitability. This is the time when managers tend to compromise the safety of staff, equipment, and environment, risking the security of radiation sources and most importantly risking overall organizational sustainability. During a financial or managerial crisis (or during management of change), the triggering action point is when the top leadership's starts using the verbal statements and comments about achieving the financial targets. As a result, the middle levels staff divert (deviance from established SOP) attention away from safety culture and safety procedures. As a result, the field and operation staff move away from safety policies, safety procedures, and already well-established safety SOPs within the workgroups. Without considering the consequences of these safety violations on the overall safety of the operations within the complex sociotechnical system. The field staff silently accepted the new orders because they perceive explicit verbal signals from the top and middle managers to just follow the new orders. To focus on performing and completing their tasks regardless of the safety concerns and outcomes. Therefore, from the systemic behaviours point of view it is important to observe how, and what statements and verbal comments made, or actions taken by the higher and middle management influence the lower field level staff's unsafe behaviours (figure 1). How comments and actions of the top and middle levels managers contribute towards creating conditions for the subsequent unsafe actions by the lower staff members. In this case the RPO and field staff's unsafe actions and subsequent the normalization of deviance (Vaughan, 1996). The examination of the case shows the strategic communication mistakes made by the $\mathrm{CEO}$ and the top leadership while communicating and conducting meetings before and after the project and major tasks. The top and middle levels managers ignore the safety of the field staff during the setting of operational goals and task planning. 


\subsection{Systemic Failure Analysis and Proposed Safety Culture Framework}

This section explores further, how systemic failures happen within sociotechnical systems. According to Perrow (1984) when within the sociotechnical organizational system components are (technologies, organizations, and individuals) tightly coupled and there are high interactions between these components or subsystems, the chances of systemic failures will be higher. Even one small mistake or one error within the complex system, can cause a systemic failure (Perrow, 1984), big events have small beginnings. System accidents are due to the complexity and unanticipated (with unexpected outcomes) interaction of multiple components (two or more). The complexity in the socio-technical system is due to interaction effects between components and the dynamic relationships (Perrow, 1984). Complex socio-technical systems can create conditions that give rise to errors, mistakes and violations by the people operating within the system. If technical staff members not following the wellestablished operating procedures and are bypassing procedures through shortcuts, it is creating failures and accidents. Because when the system interactions are dynamic and the situation is changing fast, any small deviation from set procedures can start the uncontrollable event. Therefore, operators will be unable to control and manage such an unknown and an unexpected event.

Therefore, in the ISPL case, the over-exposure accident cannot be attributed to individual mistakes or errors by workers but rather to the dysfunction of the leadership actions and decisions. When components, such as the high risks technology, untrained and unskilled humans and poorly designed organizational procedures are in the organization it will increase complexity and possible systemic failure. It is evident from case study that the decisions making, and communication systems have dynamic relations and were influencing the staff safety behaviours. Due to this inherent complexity of technology and human behaviour interaction, unpredictability and unknown ability within the system is natural outcome. Therefore, technical staff not following SOPs in the complex systems are vulnerable to mistakes, errors and resulting accidents. Systemic failures cannot be understood by explaining individual component failure within the system. The human error alone was not the only cause of the overexposure as suggested by the CEO of the company. It was overall organizational culture for safety integrated with the goals set, communication, and other business decisions making to save the company from going bankruptcy. Moreover, incidents and mistakes were happening repeatedly within ISPL due to the preconditions of handling mistakes and complexities (Reason, 1990). Systematic accidents are the manifestation of defective organizational process and unsafe behaviours at a systemic level. Systemic failures within the ISPL happening due to the poor safety culture, decision making, not respecting the regulator, and not following standard operating procedures, ineffective communications, poor rewards and incentives, lack of leadership for safety, lack of senior managers' commitment to safety, etc. Because of these defective organizational processes, working culture behaviours of lower operational staff became deviation from safety procedures. The working conditions and workplaces become perfect for individuals and teams to make errors, violations, and mistakes. If it is a normal and accepted behaviour in the organization not to follow safety standards, and there is a lack Sukkur IBA Journal of Management and Business - SIJMB | Vol 8 No. 2 July - December 2021 @ Sukkur IBA University 
of safety systems, and there are no layers of correcting and stopping mistakes and errors. The organization will have an accident culture or "culture of accidents". As we know in the case, the middle manager, RPO and field operations staff were not following safety-related SOPs and regulatory requirements, which was a clear sign of overall systemic level issues. This accident case study helped us to understand how top leadership statements and actions can influence in developing new perceptions and assumptions among the middle and lower levels staff. These lower-level staff members quickly adapted new behavior and created new working processes to perform the tasks and to achieve the results. These systemic level attitudes and norms were established in the minds of staff without any written documents. The systemic levels behaviors and actions resulted in visible mistakes, error, bypassing systems SOP, slips by the operating staff, etc. Once the staff accepted new safety-related norms and decisions, and the new safety mindset was established, a series of wrong decisions and actions both by senior and lower-level managers started. Systemic failures and accidents started to happen within the new culture of accidents.

\subsection{Systemic Analysis of the Case Accident}

This section provides a systemic analysis of the leadership actions to manage early events and situations that led ultimately to the major radiation overexposure accident. The first situation was when the radiation doses were increasing and one worker got higher doses, the RPO informed the CEO. The CEO then suggested some extra benefits and over time rather than seriously finding the reasons for this increase. Mr George and Mr Mark never showed any interest in knowing the root causes of higher radiation doses. They could have asked RPO and other staff members to discuss why it hopped and ask for suggestions how to manage such a situation. The staff safety and the operation safety not discussed in the meeting and no preventive actions were taken. The second event, when the source fallen out of the vehicle during driving, but the driver remains unaware of it for some time. The source was found without any loss or damage but the leadership and RPO were less interested in asking the important questions; how and why did this happen, what was the SOP? Why did our staff not follow the SOP? What can we change to improve our SOPs to stop such incidents from happening next time? Are we treating our staff well? What kind of work conditions we are providing to our staff? What is missing in work safety culture, and do we need to retrain our staff on safety? Top leadership, the CEO, and the technical director, on the other hand, were encouraging staff to cover up incidents. They wanted to keep these incidents to themselves with the mindset of "no need to share our weakness to others (to regulator). Top leadership were looking for these safety violations incidents from a business manager's (CEO) point of view. CEO and top management blame field staff and saw it as an unfortunate incident due to the negligence of a few employees. CEO justified that staff just made few errors and mistakes, as an occupational hazard and it happens in all technical organizations. CEO safety assumptions and beliefs were far from positive safety culture perspectives. Figure 1 provides the link between basic assumptions and behaviors.

Sukkur IBA Journal of Management and Business - SIJMB | Vol 8 No. 2 July - December 2021 @ Sukkur IBA University 


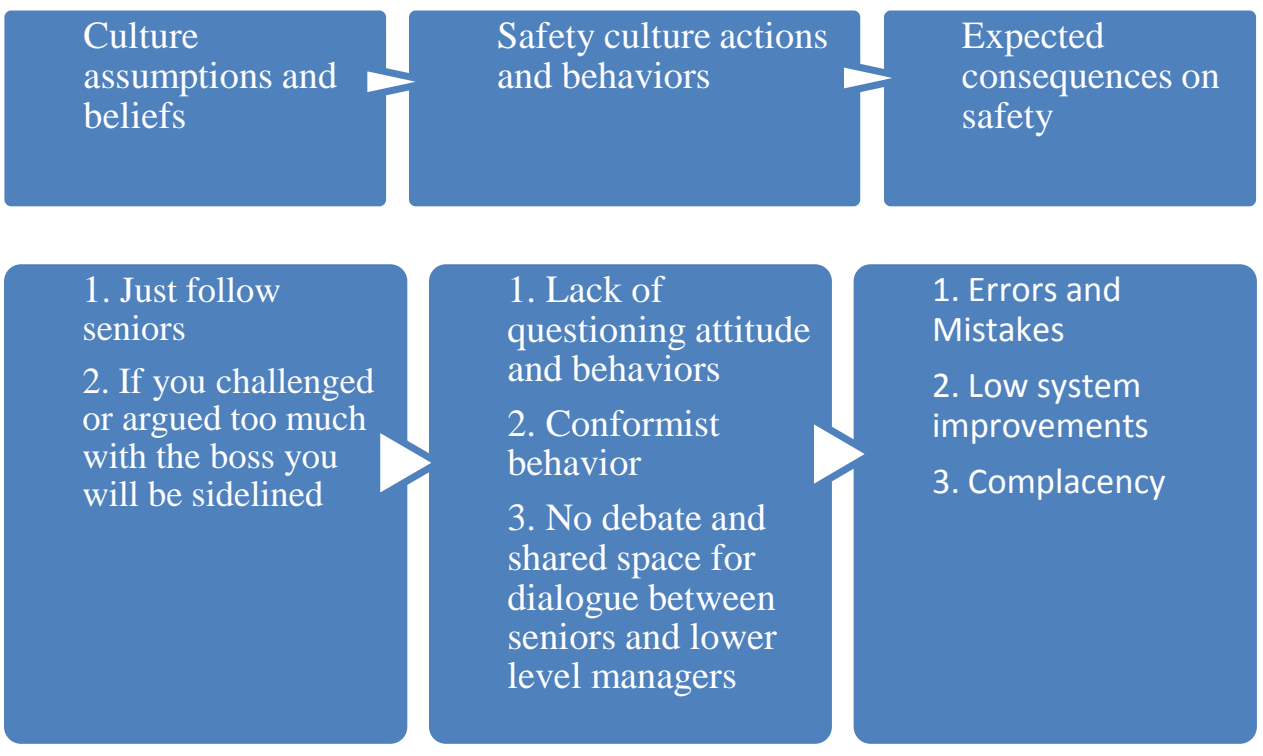

Figure 1. Link between assumptions, behaviors and consequences

The lack of safety mindfulness at top leadership and it cascaded down to the field technical staff from RPO (the middle) to lower levels. Senior management of the organization was not only disrespecting the regulator but also disregarding regulatory requirements. They were attempting to manage technical and high-risk operations with very unsafe attitude and assumptions. Leadership was more focus on the business financial side to survive by lowering the fixed costs by firing staff without realizing the consequences on safety. This is an important dilemma for all small, medium, or even large sociotechnical organizations during the economic recession. On the other hand, there is a dilemma for the regulator, how much regulatory powers to use, how tough or soft they must regulate the licensee organization especially during the financial crisis time and not to kill the business. These key decisions and situations indicate senior manager were facing systemic level issues before the staff over-exposure accident. Moreover, the importance of balancing the business goals/objectives and the task planning along with safety goals and objectives setting. ISPL top management did not define safety goals and safety behaviors during setting business goals setting and operational planning. Leadership demonstration the poor safety culture behaviors when it was needed the most to set safety first, after the loss of source incident. Leadership of the organization was not respecting regulator and licensing requirements. Senior managers were not respecting safety SOPs and safety culture norms provided by the regulator.

During the project meetings/post-project meetings staff are not allowed to share concerns, and raise relevant safety issues, which set the stage for the deviation away from safety culture. No questioning attitude and no safety culture behaviors / norms 
were practice by the management and the staff during those meetings. Staff accepted orders to perform tasks without showing concern for safety and without any feedback to senior managers. Top management supporting the cover-up attitude. Which further reinforced lower staff assumptions and behaviors toward compromising safety. During performing technical tasks staff was not following SOPs and disregarding the safety requirements. Top leadership was not allowing lower-level staff to question and challenge the actions and decisions by the top leadership during the meetings. As indicated top management was keeping business goals above safety goals and regulatory requirements. Top management was ignoring small safety incidents with not reporting incidents mindset. Technical staff was just performing tasks and not contributing to improve the safety system. Top management not consider the technical staff as valuable team members. These conditions and incidents created scenario for systemic failures and accidents in organization and the figure 2 explains the process further.

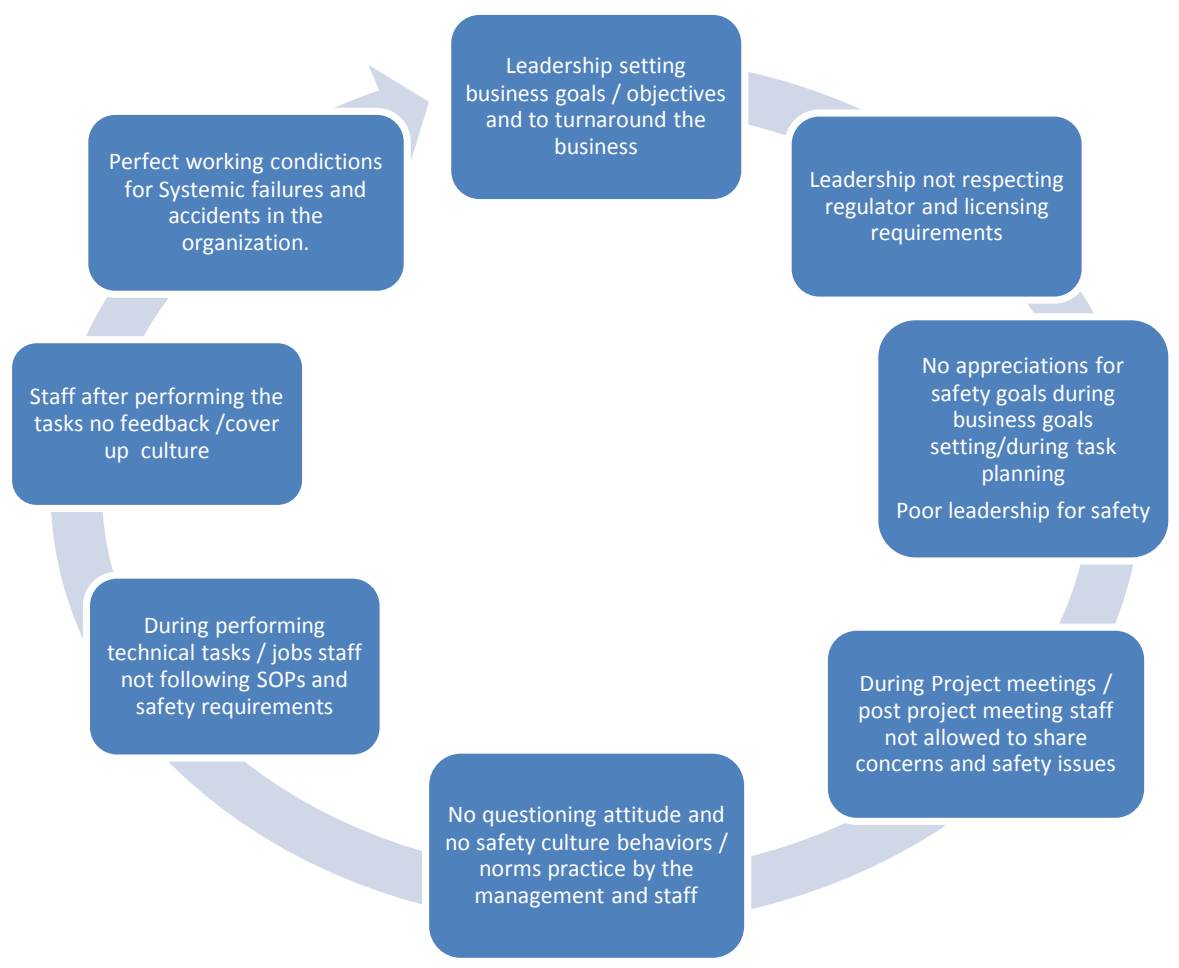

Figure 2. The Systemic process mapping of the case accident of radiation overexposure.

Vaughan (Vaughan, 1996) explains the normalization of deviance, when people in the organization become so insensitive to deviant practices that it no longer feels wrong to modify the standard work process and the working group culture. These deviant behaviors may occur due to pressure of time, cost, peer pressure or exiting design or when the correct work processes were difficult to follow. Workers justify deviant Sukkur IBA Journal of Management and Business - SIJMB | Vol 8 No. 2 July - December 2021 @ Sukkur IBA University 
actions as necessary to perform the task and achieve the outcomes. The new normalized behaviors are justified as under the concept of acceptable risks (Vaughan, 1996). Soon the new normal behavior becomes the work culture new norm "this is the way we do it in our unit". The deviant behavior is set as the new workgroup standard and the new practices become the new normal. The new deviance unsafe behavior is integrated in the work process culture without a safety mindset to achieve tasks outcomes objectives set by the organization leadership. In such situations, top leadership may or may not have the knowledge about the new unsafe behaviors but in ISPL case, they had little interest in the safety outcomes. The culture is no more the safety culture when the organization or unit working culture is the culture of normalization of deviance and violations. Staff become less committed in following and practicing safety norms and standards set by the regulator or by the organization themselves. This can be due to leadership setting business and financial goals and performances targets without considering safety goals. It is due to the human capacity to adapt and change behaviors to survive in the new organizational conditions and new expectations at work (Jackall, 2010).

\subsection{Safety Culture Improvements Framework: Proposed}

The ISPL case has provided an opportunity for us to record (Dekker, 2011) and analyse systemic failure. How deviant behaviours are normalized (Vaughan, 1996) at system levels and result in the systemic failure. Normalization of deviance refers to a process where small changes -new behaviors, technical/physical/social anomalies or other variations that represent slight deviations from the normal course of events - gradually become the norms (Vaughan, 1996). This research suggests the framework (figure 3) for systemic failure analysis and safety culture improvements. Our analysis indicates that to understand systemic failure we must first understand the safety culture within the sociotechnical system. Safety culture is a systemic level concept, and it has both normative (safety) and emerging (culture) characteristics within sociotechnical system. Therefore, we must understand safety culture as a system-level concept, integrated within the organizational process, technology, and the people interactions. Safety culture is not just part or sub system of organizational culture. Safety Culture within high reliability and high risks organizations is a comprehensive system itself covering every aspect of organizational life. One of the observations from the case study that if top management's decisions, actions, and statements give indications of poor safety behaviour then it would have negative multiplier effects on overall safety culture behaviours at lower levels managers. Therefore, the top and middle levels leadership and managers have major responsibility for safety culture and leadership for safety behaviours within the organization. Hence, within the high-performance sociotechnical system, overall safety must be the desired objective for the organization's culture. Therefore, safety culture must provide understanding about what types of culture, behaviours, values, actions, basic assumptions, and norms will result in good safety outcomes and what types of culture, behaviours, values, actions, norms, basic

Sukkur IBA Journal of Management and Business - SIJMB | Vol 8 No. 2 July - December 2021 @ Sukkur IBA University 


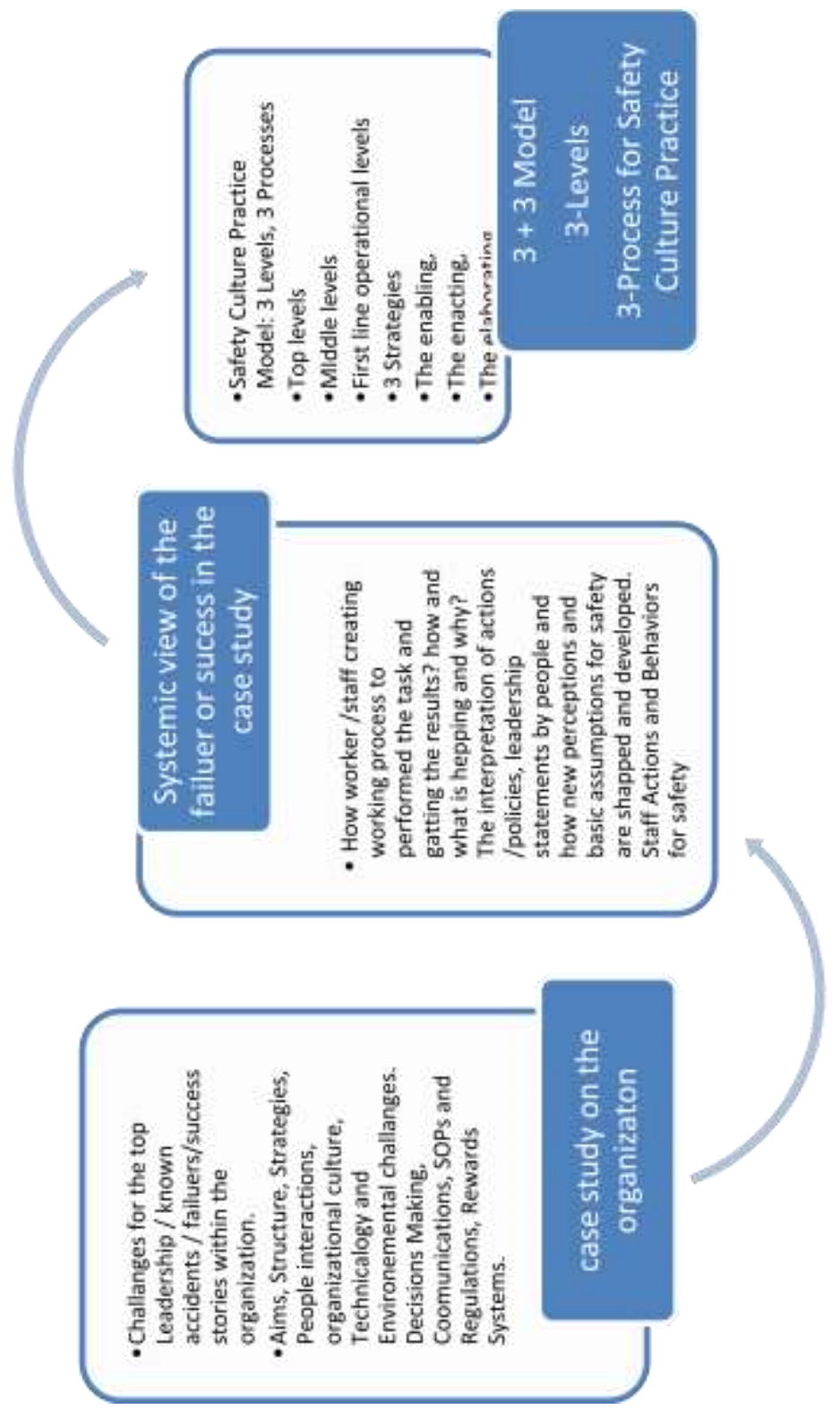

Figure 3. Three-stage approach for organizational level systemic analysis, first, development of a detail case study, secondly, systemic analysis of the case study events and third the safety culture practice and outcomes assumptions will result in poor safety outcomes and possible accidents. The analysis of the accident situation shows how small events can create system-level failures and accidents. 


\subsection{Safety drives in all 3 levels}

The case study provides clear support that within sociotechnical systems and highreliability organizations leadership must set clear safety goals and measurable outcomes along with every business goal and operational task. According to Schein (2010) "a leader should be creating and managing the corporate culture". Direct attention by the CEO and top leadership towards safety culture norms and SOPs are important for middle and lower-level managers to follow. Top leadership is responsible for developing questioning culture and shared space to encourage lower staff to share concerns and opinions regarding operational safety and work process deviance. If lower and middle levels staff have no opportunity and freedom to challenge top leadership for unsafe and against SOP violations. It will be an example of leadership for safety failure and operations moving towards the systemic failures. Top leadership is also responsible for the resource allocations for safety-related activities. Leadership must also conduct safety risks or threats identification and work process risk analysis regularly. They must seek feedback and information from middle and lower levels managers if there are any deviance and process SOP violations within a working culture. Senior leadership is responsible to mobilize people and staff towards reducing those safety risks and work process violations. The role of leadership is to design socio-technical system to have the self-learning processes from mistakes and near-miss incidents. There must be an innate intelligence within the system (the self-reflection and feedback system) to improve the practice from those learnings. If there is no system intelligence of learning from mistakes and errors and improvements of policies and work process it is a leadership failure. Leadership must share learnings from incidents and accidents openly without blaming any person or team. The focus must be to improve the overall system and safety culture without focusing too much on individual mistakes and errors.

Safety Culture Practice 3 Processes (Vogus, 2010)

Three main processes of safety culture practices in organizations.

- Enabling,

- Enacting,

- Elaborating.

Enabling means communication and drawing attention towards safety-relevant aspects with the organizational culture. This process will make it possible for people to translate safety aspects into meaningful activities in their daily work context and systems. These enable conditions such as emotional and physical safety to speak up in front of others. Having the shared space where the importance of safety is acknowledged, and safety is turn into practice by acting on it. Enacting the process for the safety culture requires highlighting and accurately representing latent and manifesting all the threats to safety and indicating all the negative behaviors towards safety and working together to reduce them. Finally, the elaborating process for the safety culture means to enlarge and continuously refine practices. In this process, people rigorously are reflecting on safety outcomes and using feedback to modify enabling practices and enacting processes. These processes help people in organization to perform safer practices. When these

Sukkur IBA Journal of Management and Business - SIJMB | Vol 8 No. 2 July - December 2021 (C) Sukkur IBA University 
three process are embedded within the safety practices, it creates a coherent safety culture with sustains safety performance and helps further improve safety practices. (Vogus, 2010). Finally, the paper shows that many accidents can be avoided simply by following SOPs and allowing people to ask questions and raise issues before any new tasks or new project start-up. Only if the middle or senior managers do not rush to perform certain tasks without spending time in planning and discussing the safety implementation plan with the field and technical team staff before the task itself. It may be a good business decision, within the high reliability and high-performance organizations, where workers conduct non-destructive tests using the radioactive source as their core activities.

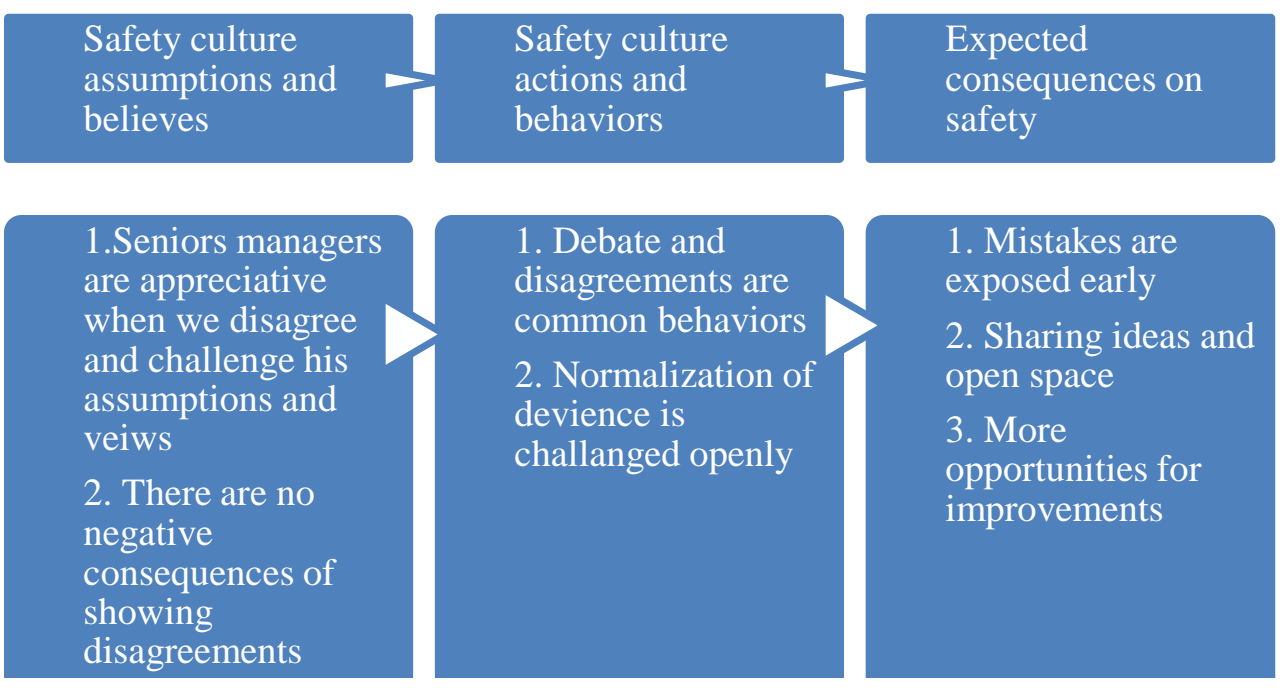

Figure 4. New assumption, new behaviours and expected consequences on performance

It is apparent that following (with commitments) the regulatory safety requirements and practicing leadership for safety are the most important functions for senior and middle levels managers in all such high-reliability organizations. Figure 4 provide the link how leadership in organization can influence the basic assumptions, behaviours, and consequences. Leadership has main task and function within high risks and high reliability sociotechnical organizations to influence towards the safety positive assumptions and safe behaviours.

This research also shows that there are always opportunities for improvements in every minor incident and from previous mistakes made in the organization. However, these opportunities for improvements will only be possible if leadership for safety is clear and committed within the organization. Furthermore, the learning from mistakes and sharing of new learning within an organization is well established and the organization's culture encourages safety culture behaviours. If workers are not afraid to speak openly Sukkur IBA Journal of Management and Business - SIJMB | Vol 8 No. 2 July - December 2021 (C) Sukkur IBA University 
or are not afraid of losing jobs, there is always an opportunity to learn and improve safe work systems and to remove or stop unsafe behaviours and actions.

Author Contributions: In this paper, I am the only author and there is no second author.

Data Availability Statement: We conducted a case study therefore there is no data or data collection.

Conflict of Interest: There is no conflict of interest during conducting this research and publication.

Funding Information: We never applied for any funding for this research project.

\section{References}

Dekker, S. (2011). The complexity of failure: Implications of complexity theory. Journal of Safety Science, 939-945.

Fortune, J., \& Peters, G. (1994). System Analysis of Failures as a Quality Management Tools. British Journal of Management, Vol. 5, 205-313.

Fortune, J., \& Peters, G. (1995). Learning from Failure - the Systems Approach. UK: Wiley.

IAEA. (2009). The Radiological Accident in Nueva Aldea. Vienna Austria.

IAEA. (2011). Radiation Safety in Industrial Radiography. Vienna Austria: IAEA.

IAEA. (2014). The Radiological Accident in Lia Georgia. Vienna Austria.

IAEA. (2016). Human and Organizational Aspects of Assuring Nuclear Safety — Exploring 30 Years of Safety Culture. International Conference IAEA. Vienna Austria.

IAEA. (2018). The radiological accident in Chilca. Vienna Austria.

IAEA. (n.d.). Radiation Safety in Industrial Radiography. IAEA.

Jackall, R. (2010). Moral Mazes. UK: Oxford University Press.

Perrow, C. (1984). Normal Accidents: Living with High-Risk Technology. USA: Basic Books.

Price, M. R. (2015). When Doing Wrong Feels So Right: Normalization of Deviance. Journal of Patient Safet.

Reason, J. (1990). Human Error. UK: Cambridge University Press.

Reiman, T. (2014). Does the concept of safety culture help or hinder systems. Journal of Accident Analysis and Prevention, 5-15.

Schein, E. H. (2004). Organizational Culture and Leadership, 3rd ed. San Francisco: JosseyBass Publishers.

Schein, E. H. (2013a). Safety Management in Context Workshop. Ticino, Switzerland.

Schein, E. H. (2016b). Human and Organizational Aspects of Assuring Nuclear Safety Exploring 30 Years of Safety Culture. Vienna, Austria: IAEA.

Schein, E. H., \& Schein, P. A. (1985). Organizational Culture and Leadership. San Francisco: Jossey-Bass Publishers.

Vaughan, D. (1996). The Challenger Launch Decision. Chicago.

Vogus, T. J. (2010). Doing No Harm: Enabling, Enacting, and Elaborating a Culture of Safety in Health Care. Academy of Management Perspectives, 60-77.

Sukkur IBA Journal of Management and Business - SIJMB | Vol 8 No. 2 July - December 2021 C Sukkur IBA University 